\title{
Secular Trends in the Incidence of Migraine in China from 1990 to 2019: A Joinpoint and Age-Period-Cohort Analysis
}

\author{
Yufeng Wang $\mathbb{B}^{1,2, *}$ \\ Xueying Huang ${ }^{1, *}$ \\ Suru Yue' \\ Jie Liu' \\ Shasha $\mathrm{Li}^{1}$ \\ Huan Ma' \\ Liren $\mathrm{Hu}^{\prime}$ \\ Jiayuan $\mathrm{Wu}^{1,2}$
}

'Clinical Research Service Center, Affiliated Hospital of Guangdong Medical University, Zhanjiang, Guangdong, 52400I, People's Republic of China ${ }^{2}$ Collaborative Innovation Engineering Technology Research Center of Clinical Medical Big Data Cloud Service in

Medical Consortium of West Guangdong Province, Affiliated Hospital of

Guangdong Medical University, Zhanjiang, Guangdong, 52400 I, People's Republic of China

*These authors contributed equally to this work
Background: Migraine is a common disorder of the nervous system in China, imposing heavy burdens on individual and societies. Optimal healthcare planning requires understanding the magnitude and changing the trend of migraine incidence in China. However, the secular trend of migraine incidence in China remains unclear.

Methods: Data were collected from the Global Burden of Disease Study 2019 in China from 1990 to 2019 to investigate changes in the incidence rate of migraine. The average annual percent change and the relative risk were calculated using the joinpoint regression model and the age-period-cohort model, respectively.

Results: From 1990 to 2019, the age-standardized incidence rates of migraine in China increased by $0.26 \%$ (95\% CI: 0.22 to 0.31 ) and $0.23 \%$ (95\% CI: 0.19 to 0.28 ) per year in males and females, respectively. Age effects exerted the most significant impact on migraine incidence. Period effects showed a slightly decreasing trend in the incidence of migraine. In terms of cohort effects, people born after the 1960s presented a higher risk of migraine as compared with the total cohort, with the incidence risk of migraine increasing with birth cohorts.

Conclusion: Migraine incidence shows an overall increasing trend in China, with a significant gender difference. A comprehensive understanding of the risk characteristics and disease pattern of migraine could allow the early detection of persons with a high risk of developing migraine and promote the development of timely intervention measures to relieve this burden effectively.

Keywords: migraine, incidence, secular trend, joinpoint regression analysis, age-periodcohort model

\section{Introduction}

Migraine is the second cause of years lived with disability in 2016 in the world, and people living with migraine are greatly influenced by this burden. ${ }^{1}$ Using a large population-based nationwide sample, a previous study in Turkey reported an above $2.4 \%$ incidence rate of migraine. ${ }^{2}$ In China, migraine is also a concern of public health. With a population of over 1.3 billion, $20 \%$ of the total in the planet, China has the largest migraine population worldwide. ${ }^{3}$ Improving the epidemiological understanding of migraine is the basic requirement to promote the diagnosis and treatment of migraine and the rational allocation of healthcare resources. Thus, the incidence of migraine and its possible changes could afford assistance to illustrate the risk factors of developing the disease.
Correspondence: Jiayuan Wu

Email wujiay@gdmu.edu.cn 
Present studies on migraine included small sample size, limited localities, and high rates of under-diagnosis and misdiagnosis. ${ }^{4}$ Moreover, the disease burden of migraine is easily overlooked because this disease is nonfatal. In addition, the long-term changes in migraine incidence are difficult to determine because migraine is multifaceted and fragmented. The Global Burden of Disease Study 2019 (GBD 2019) assessed the disease burden of migraine by age, sex, year, and location by using a normative approach. GBD data can produce abundant information and up-todate estimates of migraine burden at the global, regional, and national levels., ${ }^{5,6}$

Migraine incidence may be affected by obesity, metabolic syndrome, educational level, and socioeconomic status, and these risk factors vary with chronological age, time period, and birth cohort. ${ }^{7}$ However, descriptive analysis with traditional methods cannot eliminate the confounding effects of age, period, and cohort, and the results may have some limitations. ${ }^{8}$ Meanwhile, age-periodcohort models have an excellent advantage in evaluating the age, period, and cohort effects on the disease burden. Age effects exhibit a various risk of the outcome associated with different age brackets. Period effects express impacts of an intricate combination of historical events and environmental factors. Moreover, birth cohort effects represent the influence of physical and social exposure that appear earlier in life process and accumulate as time progresses. ${ }^{9}$ Thus, age-period-cohort models might have an advantage in quantifying the disease burden and provide researchers with significant information to evaluate the pathogenesis of migraine. In this paper, we sought to analyze the secular trend of migraine incidence from 1990 to 2019 in China.

\section{Methods}

\section{Data Source}

The GBD 2019 integrated literature research, monitoring and investigation information, inpatient and outpatient data, medical insurance situation, and other information to evaluate the incidence, prevalence, mortality, and disability adjusted life years of 369 diseases, injuries, and 87 risk factors in 204 countries from 1990 to 2019. Details of the GBD 2019 data, statistical modeling, and metrics have been reported in previous studies. ${ }^{10-12}$ Our study focused on the secular trend in the incidence of migraine in China based on the GBD 2019 data. In GBD 2019, migraine was defined in accordance with the International Classification of Headache Disorders. Migraine is a primary headache disorder, typically characterized by recurrent moderate or severe unilateral pulsatile headache disorders. The GBD 2019 do not distinguish between migraine with and without aura as most epidemiological studies report on overall migraine only. Ethical approval was waived for this study because the GBD data are anonymous and publicly available.

\section{Joinpoint Regression Analysis}

Analysis of the long-term trend is crucial to the comprehension of disease incidence. Joinpoint Regression Program 4.5.0.1 was used for joinpoint analysis. The regression model was established to calculate the regression coefficient, annual percent change (APC), average annual percent change (AAPC), and the corresponding 95\% confidence intervals (CIs). ${ }^{13,14}$ The basic idea of joinpoint analysis is described to divide a secular trend line into some statistically significant trend sections by model fitting, and each section is described by continuous linear expression.

\section{Age-Period-Cohort Analysis}

Age-period-cohort model is commonly used to analyze and estimate the net age, period (year of survey), and cohort (year of birth) effects on incidence trends. ${ }^{15,16}$ This model is developed based on Poisson distribution and requires an equal time interval in age, period, and cohort. Otherwise, information in the adjacent queues will overlap. The age-period-cohort model can be expressed as follows:

$$
\mathrm{Y}_{j}=\mu+\alpha \text { age }_{j}+\beta \text { period }_{j}+\gamma \text { cohort }_{j}+\varepsilon_{i}
$$

where $Y_{j}$ denotes the response variable of the net effect on migraine incidence for group $j, \alpha, \beta$, and $\gamma$ denote the coefficients of age, period, and birth cohort of the ageperiod-cohort model, respectively. $\mu$ denotes the intercept of the model. $\varepsilon_{i}$ is expressed as the residual of the ageperiod-cohort model. In the GBD 2019 database, the incidence of migraine was not recorded for persons aged under 5 years. Moreover, the population over 95 years of age was summarized as one group. The occurrence of migraine in this age group is rare, and its age grouping does not satisfy the data format of the age-period-cohort model. Thus, this age group was excluded in this study. Data for migraine were organized by 5 -year periods from 1990 to 2019, 5-year age groups from 5 to 95, and 
Table I The Sex-Age-Specific Rates of Migraine in China in 2019 and Their Percentage Changes from 1990 to 2019

\begin{tabular}{|c|c|c|c|c|}
\hline \multirow[t]{2}{*}{ Categories } & \multicolumn{2}{|c|}{ Males } & \multicolumn{2}{|c|}{ Females } \\
\hline & $\begin{array}{c}\text { Rates in } 2019,95 \% \text { UI } \\
\text { (per } 100,000 \text { Population) }\end{array}$ & $\begin{array}{c}\text { AAPC, } 95 \% \mathrm{Cl} \\
(\%, 1990 \text { to } 2019)\end{array}$ & $\begin{array}{c}\text { Rates in } 2019,95 \% \text { UI } \\
\text { (per } 100,000 \text { Population) }\end{array}$ & $\begin{array}{c}\text { AAPC, } 95 \% \mathrm{Cl} \\
(\%, 1990 \text { to } 2019)\end{array}$ \\
\hline ASR & 697.27 (608.73 to 787.11$)$ & $0.26(0.22 \text { to } 0.31)^{*}$ & I 247.58 (| 100.46 to 1400.14$)$ & $0.23(0.19 \text { to } 0.28)^{*}$ \\
\hline $5-9$ years & 717.89 (44I.75 to 1094.9$)$ & $0.48(0.40 \text { to } 0.55)^{*}$ & | 332.56 (827.74 to 2033.1 I) & $0.35(0.27 \text { to } 0.43)^{*}$ \\
\hline $10-14$ years & I257.75 (880.00 to I670.56) & $0.34(0.28 \text { to } 0.40)^{*}$ & 2193.52 (1547.22 to 2939.46$)$ & $0.27(0.21 \text { to } 0.33)^{*}$ \\
\hline $15-19$ years & $1012.72(67 \mid .66$ to 1452.26$)$ & $0.13(0.07 \text { to } 0.20)^{*}$ & $1678.92(1119.40$ to 2347.28$)$ & $0.14(0.08 \text { to } 0.20)^{*}$ \\
\hline $20-24$ years & 952.47 (604.25 to 1426.09) & $0.12(0.07 \text { to } 0.18)^{*}$ & $1610.47(1012.15$ to 2429.49$)$ & 0.12 (0.07 to 0.17$)^{*}$ \\
\hline $25-29$ years & $985.74(611.65$ to 1437.09$)$ & $0.16(0.11 \text { to } 0.22)^{*}$ & $1767.49(1101.8 \mid$ to 2592.97$)$ & $0.15(0.11 \text { to } 0.19)^{*}$ \\
\hline $30-34$ years & 890.21 (582.09 to 1269.34$)$ & $0.20(0.15 \text { to } 0.25)^{*}$ & $1640.39(1089.9 \mid$ to 2377.83$)$ & $0.25(0.16 \text { to } 0.33)^{*}$ \\
\hline $35-39$ years & 885.58 (572.89 to 1251.09$)$ & $0.39(0.32 \text { to } 0.45)^{*}$ & $1643.88(1071.34$ to 2351.12$)$ & 0.35 (0.28 to 0.42$)^{*}$ \\
\hline $40-44$ years & 799.77 (498.75 to II5I.46) & $0.35(0.28 \text { to } 0.43)^{*}$ & I503.74 (935.3| to 2168.64$)$ & $0.34(0.29 \text { to } 0.39)^{*}$ \\
\hline $45-49$ years & 618.99 (394.59 to 879.47$)$ & $0.27(0.21 \text { to } 0.33)^{*}$ & I I 45.59 (748.29 to I632.25) & $0.30(0.23 \text { to } 0.37)^{*}$ \\
\hline $50-54$ years & 546.55 (342.82 to 800.42$)$ & $0.33(0.26 \text { to } 0.39)^{*}$ & 1022.17 (625.80 to I509.67) & $0.30(0.23 \text { to } 0.37)^{*}$ \\
\hline $55-59$ years & 413.29 (263.54 to 600.48$)$ & $0.25(0.19 \text { to } 0.30)^{*}$ & 776.67 (506.35 to II09.47) & $0.34(0.28 \text { to } 0.39)^{*}$ \\
\hline $60-64$ years & 280.61 (166.60 to 421.09$)$ & $0.20(0.15 \text { to } 0.24)^{*}$ & 496.78 (299.69 to 743.97$)$ & $0.30(0.24 \text { to } 0.35)^{*}$ \\
\hline $65-69$ years & $207.67(|27.2|$ to 296.37$)$ & $0.16(0.13 \text { to } 0.19)^{*}$ & 372.43 (221.19 to 549.48$)$ & $0.25(0.20 \text { to } 0.31)^{*}$ \\
\hline 70-74 years & $185.16(|14.5|$ to 274.66$)$ & $0.16(0.12 \text { to } 0.20)^{*}$ & 342.12 (214.49 to 499.09$)$ & $0.28(0.22 \text { to } 0.34)^{*}$ \\
\hline $75-79$ years & 199.91 (I22.52 to 284.17$)$ & $0.14(0.11 \text { to } 0.18)^{*}$ & 385.59 (235.87 to 55 I.49) & $0.27(0.20 \text { to } 0.34)^{*}$ \\
\hline $80-84$ years & 198.52 (I27.53 to 287.72$)$ & $0.06(0.04 \text { to } 0.08)^{*}$ & $391.92(255.85$ to 572.60$)$ & $0.30(0.24 \text { to } 0.36)^{*}$ \\
\hline $85-89$ years & |50.8| (98.26 to 213.74$)$ & $0.02(0.01 \text { to } 0.03)^{*}$ & 262.21 (164.98 to 375.93$)$ & $0.23(0.20 \text { to } 0.26)^{*}$ \\
\hline $90-94$ years & 83.21 (56.90 to II8.5I) & $-0.02(-0.03 \text { to }-0.01)^{*}$ & II 5.60 (77.84 to 165.73$)$ & $0.05(0.03 \text { to } 0.06)^{*}$ \\
\hline
\end{tabular}

Note: *Indicated the AAPC was significant different from zero at the alpha $=0.05$ level.

Abbreviations: Ul, uncertainty interval; ASR, age-standardized rates; AAPC, average annual percent change; Cl, confidence interval;

correspondingly consecutive 5-year birth cohort groups starting from 1900-1904 to 2015-2019 in this study.

The independent effects of age, period, and cohort are difficult to assess because of the well-known nonidentifiability problem $($ cohort $=$ period - age $)$. The ageperiod-cohort framework with the intrinsic estimator method can solve this problem. The method provided estimated coefficients for the age, period, and cohort effects. These coefficients were transformed into the exponential value $\left[\exp\right.$ (coef.) $=\mathrm{e}^{\text {coef. }}$, which denotes the incidence relative risk (RR) of age, period, or birth cohort relative to the average level of all ages, periods, or birth cohorts combined. Therefore, we used the RR representation to estimate the aggregate effects of age, period, and birth cohort. ${ }^{17-19}$ All analyses and graphics were carried out using STATA 15.0 software (StataCorp, College Station, TX, USA).

\section{Results}

\section{Descriptive Analysis}

Our study indicated that the sex-specific age-standardized incidence rates of migraine maintained an increment from 1990 to 2019. For migraine, the annual age-standardized incidence rates in males were significantly lower than those in females. The incidence rates of migraine due to age group in China in 2019 are shown in Table 1 and Figure 1. In 2019, the age-standardized incidence rates of migraine in China were 697.27 (95\% UI: 608.73 to 787.11) per 100,000 persons in males and $1247.58(95 \%$ UI: 1100.46 to 1400.14 ) per 100,000 persons in females. The top incidence rates of migraine were surveyed in the 10-14 age group, followed by the 22-44 age group in both sexes. From 1990 to 2019, trends in the sex-specific agestandardized incidence rates of migraine in China are described in Table 1.

\section{Joinpoint Regression Analysis}

From 1990 to 2019, the AAPCs of age-sex-specific rates in migraine are shown in Table 1. The age-standardized incidence rates of migraine from 1990 to 2019 increased by $0.26 \%$ (95\% CI: 0.22 to 0.31 ) in males and $0.23 \%$ (95\% CI: 0.19 to 0.28 ) in females (Figure 2). Regardless of age groups, remarkable increments in sex-specific incidence rates were also shown in migraine. Joinpoint regression analysis showed that the age-standardized incidence rates of migraine slightly decreased in males (APC $=$ 


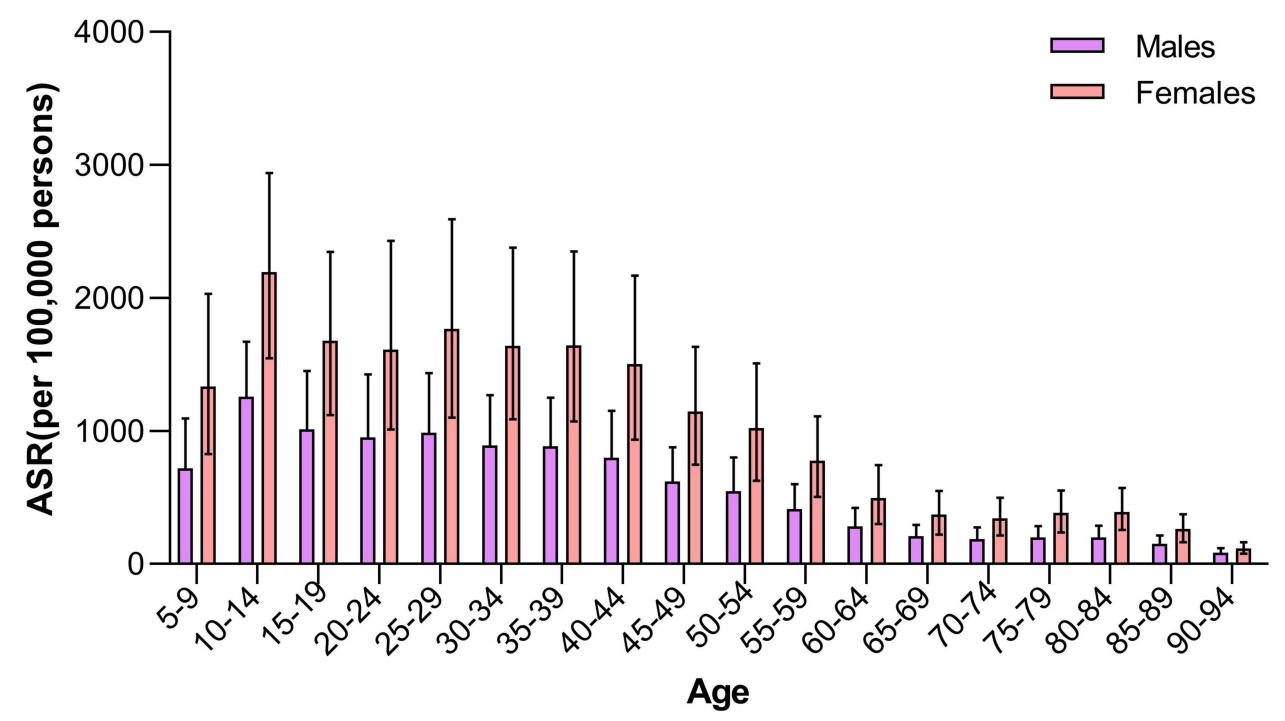

Figure I Age-sex-specific rates of migraine in China in 2019. Abbreviation: ASR, age-standardized rates.

$-0.12 \%, 95 \% \mathrm{CI}:-0.16$ to -0.08$)$ and females (APC $=$ $-0.09 \%, 95 \%$ CI: -0.12 to -0.05 ) from 1990 to 2001 . However, continuously increasing trends of sex-specific migraine incidences in China were observed from 2001 to 2019. The joinpoint regression results of sex-specific rates for migraine are presented in Supplementary Table 1.

\section{Age-Period-Cohort Analysis}

Using age-period-cohort analysis, we calculated the RRs of migraine incidence about net age, period, and cohort effects (Table 2). With the period and cohort effects unchanged, the highest RRs of migraine incidence due to age effects were found in the 10-14 age group, with 1.99 (95\% CI: 1.93 to 2.05 ) in males and 1.98 (95\% CI: 1.93 to 2.03 ) in females (Figure 3A), followed by the 25-44 age group, and then decreased starting at the 45-50 age group in both sexes. The RRs of migraine incidence due to period effects showed a mild decrease from 1.08 (95\% CI: 1.06 to 1.10 ) in 1994 to 0.93 (95\% CI: 0.91 to 0.95$)$ in 2019 for males and from 1.08 (95\% CI: 1.06 to 1.09$)$ in 1994 to 0.93 (95\% CI: 0.92 to 0.95 ) in 2019 for females (Figure 3B). The RRs of migraine incidence for birth cohort effects continuously increased from 0.66 (95\% CI: 0.54 to 0.81 ) in the $1900-1904$ cohort to 1.65 (95\% CI: 1.52 to 1.80 ) in the 2010-2014 cohort for males and from 0.66 (95\% CI: 0.55 to 0.78 ) in the $1900-1904$ cohort to 1.61 (95\% CI: 1.51 to 1.71 ) in the 2010-2014 cohort for females (Figure 3C).

\section{Discussion}

This study is the first to explore the secular trends of migraine incidence in China from 1990 and 2019 by using the age-period-cohort model. Our study showed that the estimated rate of migraine incidence in China is higher in females than in males. Migraine attacks are more severe in females than in males, leading to greater disability and a longer recovery period. ${ }^{20}$ Although the reason for this sex difference in the incidence of migraine is complicated and intricate, studies have shown that females have greater sensitivity to harmful stimuli, higher pain ratings, lower pain thresholds, and tolerance than males. In addition, females are more likely to report pain than males. $^{21}$ Moreover, sex difference in migraine incidence may be partly attributable to a combination of psychological, physical, and lifestyle factors. ${ }^{22}$ In China, females are more likely to bear a higher psychological and physical burdens than males. For example, females have a higher lifetime risk of mental disorders (eg, depression and anxiety) than males. These mental disorders are remarkably correlated with an increasing risk of migraine. ${ }^{23}$ Concerning the physiological factors, females face unique periods, such as puberty and menarche, menstruation, pregnancy, and menopause during their lifetime. The incidence of migraine could be affected by hormonal fluctuations during these women-specific biological periods. ${ }^{24-26}$ Lifestyle factors also play a crucial role in migraine. For instance, dietary sodium intake is significantly associated with migraine incidence in females but not in males. ${ }^{27}$ 


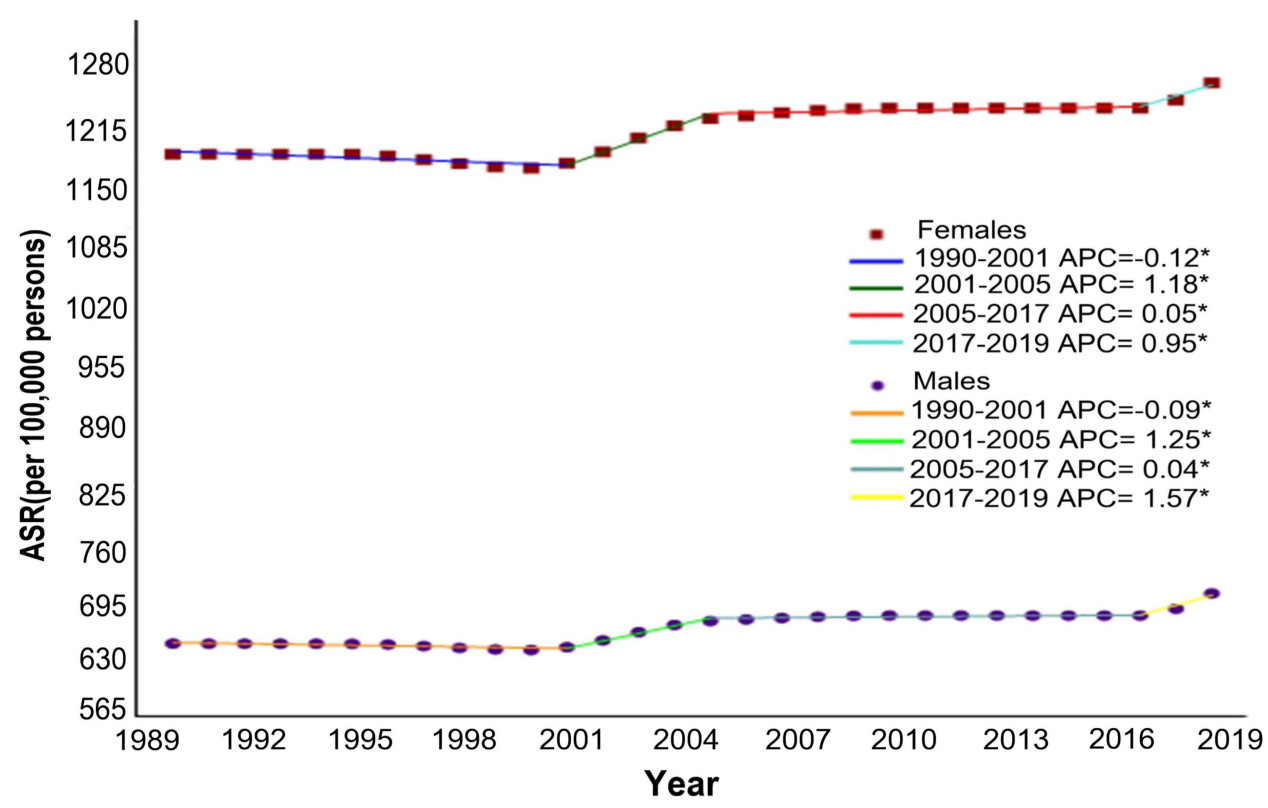

Figure 2 Joinpoint regression analysis in sex-specific age-standardized incidence rates of migraine in China from 1990 to 2019. Note: *Indicated the annual percent change is statistically significantly different from zero at the $\alpha=0.05$ level. Abbreviation: APC, annual percent change.

The trends of migraine incidence were constant over time in Western countries. A large longitudinal study in Germany found no general increase in self-reported migraine incidence over a 15 -year period. ${ }^{28} \mathrm{~A}$ case-control study from the UK showed that the migraine incidence rate was 3.69 (95\% CI: 3.66 to 3.73 ) per 1000 person-years and did not significantly change between 1994 and $2001 .^{29}$ However, results of joinpoint regression indicated that the incidence rates of migraine increased from 1990 to 2019 in China, regardless of sex and age group. Migraine is associated with various chronic diseases, such as depression, anxiety, epilepsy, and posttraumatic stress disorder. ${ }^{30,31}$ Thus, the increasing trend of migraine burden should be paid attention. Although several epidemiological studies on migraine have been conducted in the past decade, most of them were cross-sectional epidemiological studies in a given population based on questionnaires. ${ }^{32-34}$ Therefore, further longitudinal study on the general population is warranted to understand the true burden of migraine in China.

The age-period-cohort analysis showed age effects as a crucial factor for migraine. Our study deemed that children and adolescents are a high-risk group of migraine. A meta-analysis confirmed the global high burden of migraine in children and adolescents with a prevalence rate of $7.7 \%,{ }^{35}$ which may be related to the educational pattern in Asia. A questionnaire survey in Taiwan revealed that the prevalence of migraine is $6.8 \%$ in school adolescents aged 13-15 years and that students with migraine are more likely to manifest absenteeism than those with other types of headaches. ${ }^{36}$ A survey on pediatric headaches in Japan suggested that migraine is common in school children aged 6-15 years and that the disruption of daily activities caused by migraine is higher among junior high students than elementary school students. ${ }^{37}$ In China, a 9-year compulsory education is required for children under 15 years old, of which education model and student burden are similar to those in Taiwan and Japan. An epidemiological study in Shanghai reported that the proportion of migraine varies with age from $13 \%$ to $43 \%$ among children and adolescents and that the highest proportions are found at $14-15$ years of age. ${ }^{38}$ Young persons in Chinese education programs must take the 11-plus exam and face the pressure of entering a higher school and peer competition, which may partly contribute to the increased incidence of migraine. Thus, parents, schools, and societies should pay attention to children's mental health and reduce their academic burden appropriately. Compared with that in the pediatric group, migraine in the 20-44 age group manifests markedly different. A study indicated that alcohol consumption, smoking, and neck pain are the primary risk factors of migraine in adults. ${ }^{39}$ Thus, adults should adopt a healthy lifestyle. Moreover, the incidence rates in elder people are surprisingly much higher in China than in the United States. ${ }^{40}$ One probable reason is that 
Table 2 Sex-Specific Relative Risks of Migraine in China Due to Age, Period, and Cohort Effects

\begin{tabular}{|c|c|c|c|c|}
\hline \multirow[t]{2}{*}{ Factor } & \multicolumn{2}{|c|}{ Males } & \multicolumn{2}{|c|}{ Females } \\
\hline & $\mathbf{R R}(95 \% \mathrm{Cl})$ & $P$ value & $\operatorname{RR}(95 \% \mathrm{Cl})$ & $P$ value \\
\hline \multicolumn{5}{|l|}{ Age } \\
\hline $5-9$ & 1.08 (1.04 to 1.13$)$ & $<0.001$ & 1.15 (1.12 to 1.19$)$ & $<0.001$ \\
\hline $10-14$ & 1.99 (1.93 to 2.05$)$ & $<0.001$ & 1.98 (1.93 to 2.03$)$ & $<0.001$ \\
\hline $15-19$ & 1.69 (I.64 to 1.74$)$ & $<0.001$ & 1.58 (1.55 to 1.62$)$ & $<0.001$ \\
\hline $20-24$ & 1.68 (I.63 to 1.73$)$ & $<0.001$ & $1.62(1.59$ to 1.66$)$ & $<0.001$ \\
\hline $25-29$ & I.83 (I.78 to I.89) & $<0.001$ & $1.86(1.82$ to 1.91$)$ & $<0.001$ \\
\hline $30-34$ & I.74 (I.69 to I.79) & $<0.001$ & I.80 (I.76 to I.84) & $<0.001$ \\
\hline $35-39$ & I.79 (I.73 to I.85) & $<0.001$ & 1.88 (1.83 to 1.92$)$ & $<0.001$ \\
\hline $40-44$ & I.7I (I.65 to I.77) & $<0.001$ & 1.77 (I.73 to I.82) & $<0.001$ \\
\hline $45-49$ & 1.39 (I.33 to I.44) & $<0.001$ & 1.42 (I.38 to 1.46$)$ & $<0.001$ \\
\hline $50-54$ & 1.28 (I.22 to 1.33$)$ & $<0.001$ & 1.32 (I.28 to 1.36$)$ & $<0.001$ \\
\hline $55-59$ & 1.03 (0.98 to 1.07$)$ & 0.285 & 1.04 (I.01 to 1.08$)$ & 0.011 \\
\hline $60-64$ & 0.72 (0.68 to 0.76$)$ & $<0.001$ & $0.7 \mathrm{I}(0.68$ to 0.74$)$ & $<0.001$ \\
\hline $65-69$ & 0.56 (0.53 to 0.59$)$ & $<0.001$ & 0.55 (0.52 to 0.57$)$ & $<0.001$ \\
\hline $70-74$ & 0.52 (0.49 to 0.55$)$ & $<0.001$ & 0.53 (0.50 to 0.55$)$ & $<0.001$ \\
\hline $75-79$ & 0.58 (0.55 to 0.62$)$ & $<0.001$ & 0.62 (0.60 to 0.65$)$ & $<0.001$ \\
\hline $80-84$ & $0.60(0.57$ to 0.64$)$ & $<0.001$ & 0.65 (0.62 to 0.68$)$ & $<0.001$ \\
\hline $85-89$ & $0.47(0.44$ to 0.50$)$ & $<0.001$ & 0.45 (0.43 to 0.47$)$ & $<0.001$ \\
\hline $90-94$ & $0.27(0.25$ to 0.29$)$ & $<0.001$ & $0.21(0.20$ to 0.23$)$ & $<0.001$ \\
\hline \multicolumn{5}{|l|}{ Period } \\
\hline 1994 & $1.08(1.06$ to 1.10$)$ & $<0.001$ & $1.08(1.06$ to 1.09$)$ & $<0.001$ \\
\hline 1999 & $1.03(1.01$ to 1.05$)$ & 0.006 & $1.02(1.01$ to 1.04$)$ & 0.001 \\
\hline 2004 & $1.03(1.01$ to 1.05$)$ & 0.005 & $\mathrm{I} .03(\mathrm{I} .0 \mathrm{I}$ to $\mathrm{I.04})$ & $<0.001$ \\
\hline 2009 & 0.99 (0.98 to 1.01$)$ & 0.499 & $1.00(0.98$ to 1.01$)$ & 0.643 \\
\hline 2014 & 0.95 (0.93 to 0.97$)$ & $<0.001$ & 0.95 (0.94 to 0.97$)$ & $<0.001$ \\
\hline 2019 & $0.93(0.91$ to 0.95$)$ & $<0.001$ & $0.93(0.92$ to 0.95$)$ & $<0.001$ \\
\hline \multicolumn{5}{|l|}{ Cohort } \\
\hline $1900-1904$ & 0.66 (0.54 to 0.81$)$ & $<0.001$ & 0.66 (0.55 to 0.78$)$ & $<0.001$ \\
\hline $1905-1909$ & $0.69(0.61$ to 0.78$)$ & $<0.001$ & $0.67(0.61$ to 0.74$)$ & $<0.001$ \\
\hline $1910-1914$ & $0.7 \mathrm{I}$ (0.64 to 0.78$)$ & $<0.001$ & 0.69 (0.64 to 0.74$)$ & $<0.001$ \\
\hline $1915-1919$ & 0.72 (0.67 to 0.78$)$ & $<0.001$ & 0.72 (0.67 to 0.76$)$ & $<0.001$ \\
\hline $1920-1924$ & $0.74(0.69$ to 0.80$)$ & $<0.001$ & $0.75(0.7 \mid$ to 0.79$)$ & $<0.001$ \\
\hline $1925-1929$ & 0.77 (0.72 to 0.82$)$ & $<0.001$ & 0.78 (0.74 to 0.82$)$ & $<0.001$ \\
\hline $1930-1934$ & $0.80(0.75$ to 0.86$)$ & $<0.001$ & $0.82(0.78$ to 0.85$)$ & $<0.001$ \\
\hline $1935-1939$ & 0.83 (0.78 to 0.88$)$ & $<0.001$ & $0.84(0.8 \mathrm{I}$ to 0.88$)$ & $<0.001$ \\
\hline $1940-1944$ & $0.86(0.8 \mathrm{I}$ to $0.9 \mathrm{I})$ & $<0.001$ & $0.88(0.84$ to 0.91$)$ & $<0.001$ \\
\hline $1945-1949$ & 0.90 (0.85 to 0.95$)$ & $<0.001$ & 0.92 (0.88 to 0.95$)$ & $<0.001$ \\
\hline $1950-1954$ & 0.94 (0.89 to 0.99$)$ & 0.012 & $0.96(0.92$ to 0.99$)$ & 0.025 \\
\hline $1955-1959$ & 0.98 (0.94 to 1.02$)$ & 0.347 & $1.00(0.97$ to 1.03$)$ & 0.942 \\
\hline $1960-1964$ & 1.03 (0.99 to 1.07$)$ & 0.214 & $1.04(1.01$ to 1.08$)$ & 0.005 \\
\hline $1965-1969$ & I.08 (I.04 to I.I2) & $<0.001$ & 1.09 (I.06 to I.I2) & $<0.001$ \\
\hline $1970-1974$ & 1.13 (1.09 to I.17) & $<0.001$ & I.14 (I.II to I.I7) & $<0.001$ \\
\hline $1975-1979$ & $1.18(1.14$ to 1.21$)$ & $<0.001$ & $1.18(1.15$ to 1.20$)$ & $<0.001$ \\
\hline $1980-1984$ & 1.22 (1.18 to 1.25$)$ & $<0.001$ & 1.21 (1.19 to 1.24$)$ & $<0.001$ \\
\hline $1985-1989$ & $1.26(1.23$ to 1.30$)$ & $<0.001$ & 1.26 (1.24 to 1.29$)$ & $<0.001$ \\
\hline $1990-1994$ & I.3I (I.28 to I.36) & $<0.001$ & I.31 (1.28 to I.34) & $<0.001$ \\
\hline $1995-1999$ & 1.39 (I.34 to 1.44$)$ & $<0.001$ & $1.36(1.33$ to 1.40$)$ & $<0.001$ \\
\hline 2000-2004 & I.49 (I.43 to I.55) & $<0.001$ & $\mathrm{I} .46(\mathrm{I} .4 \mathrm{I}$ to $\mathrm{I} .50)$ & $<0.001$ \\
\hline $2005-2009$ & I.58 (I.50 to I.66) & $<0.001$ & I.54 (I.48 to 1.60$)$ & $<0.001$ \\
\hline
\end{tabular}

(Continued) 
Table 2 (Continued).

\begin{tabular}{|c|c|c|c|c|}
\hline \multirow[t]{2}{*}{ Factor } & \multicolumn{2}{|c|}{ Males } & \multicolumn{2}{|c|}{ Females } \\
\hline & $\operatorname{RR}(95 \% \mathrm{Cl})$ & $P$ value & $\operatorname{RR}(95 \% \mathrm{Cl})$ & $P$ value \\
\hline $2010-2014$ & $1.65(1.52$ to 1.80$)$ & $<0.001$ & I.6I (I.5I to I.7I) & $<0.001$ \\
\hline Deviance & \multicolumn{2}{|c|}{4.63} & \multicolumn{2}{|c|}{6.04} \\
\hline AIC & \multicolumn{2}{|c|}{8.76} & \multicolumn{2}{|c|}{9.36} \\
\hline $\mathrm{BIC}$ & \multicolumn{2}{|c|}{-295.02} & \multicolumn{2}{|c|}{-293.62} \\
\hline
\end{tabular}

Notes: RR denotes the relative risk of migraine incidence in a particular age, period, or birth cohort relative to the average level of all age, period, or birth cohort combined. Abbreviations: RR, relative risk; Cl, confidence interval; AIC, Akaike Information Criterions; BIC, Bayesian Information Criterions.

only patients who consulted a doctor were considered as migraine cases in the studies from the United States, which might underestimate migraine burden because a significant portion of patients with migraine do not seek medical treatment. $^{41}$

Concerning birth cohort effects, we revealed that the risk of migraine increased with the later birth cohort. Although the pathogenesis of migraine is unknown, risk factors such as obesity, metabolic syndrome, environmental pollution, stressful life events, and head and neck pain have been associated with the onset of migraine. ${ }^{42}$ The later people are born, the more susceptible they are to these risk factors in early life, leading to a higher incidence of migraine. Obesity and metabolic syndrome are long-known risk factors for migraine. ${ }^{43}$ With socioeconomic development and lifestyle change, the obesity rate and the incidence of metabolic syndrome among Chinese people have significantly increased for the past three decades. ${ }^{44}$ However, the
A

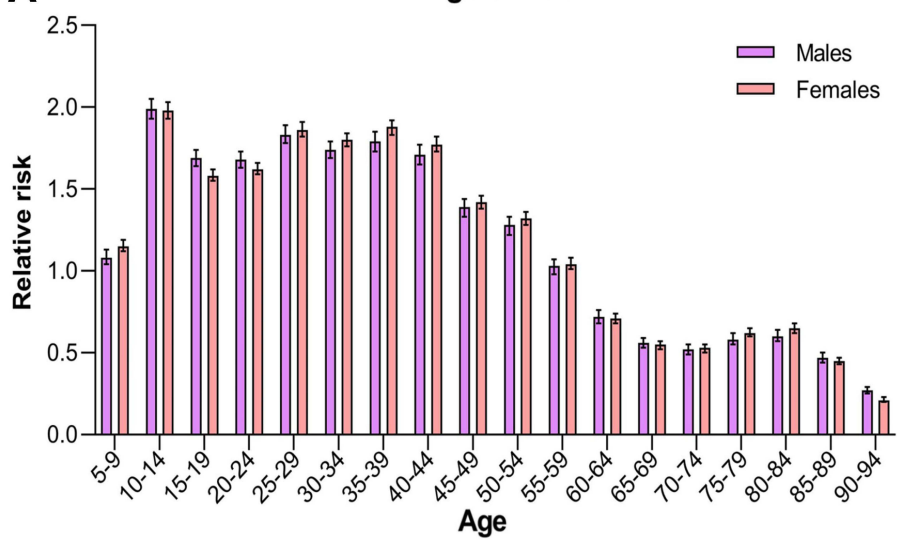

B

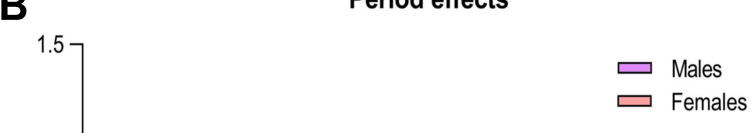

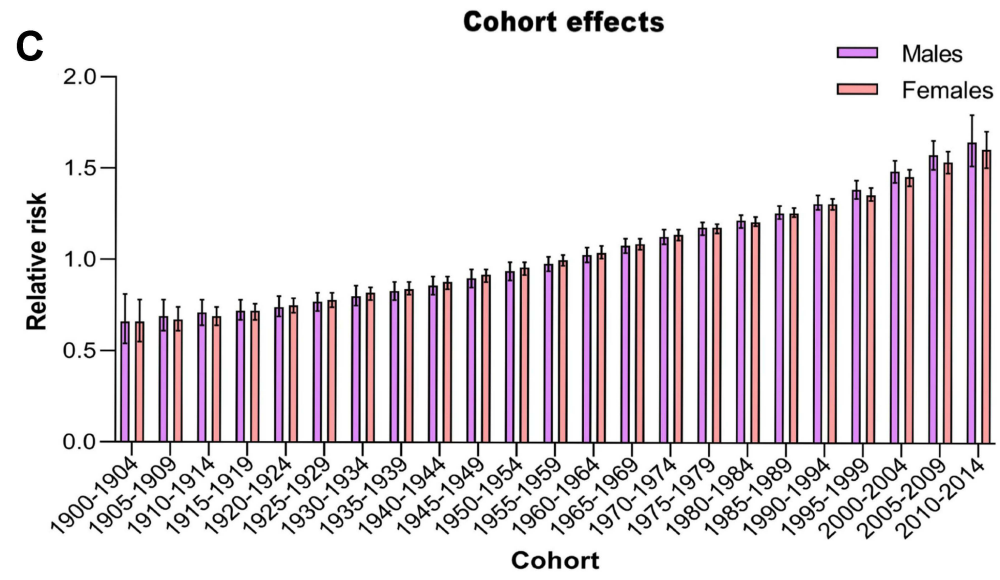

Figure 3 Relative risks of migraine in China from 1990 to 2019 due to age (A), period (B), and cohort (C) effects. 
mechanisms that link obesity and metabolic syndrome with an increased frequency of migraine are poorly understood. Moreover, although the Chinese economy has shown acquired conspicuous performance since the 1990s, environmental pollution has become increasingly serious during this period. ${ }^{45}$ An association has been established between exposure to high levels of air pollution and an increment in the number of outpatient and inpatient visits due to migraine. ${ }^{46}$ Similarly, stressful life events such as divorce are among risk factors of migraine. ${ }^{47}$ The crude divorce rate in China measured by the number of divorces per 1000 population has continuously increased from 0.33 in 1979 to 3.4 in $2019 .^{48}$ Due to the widespread use of electronic products, physical inactivity, and aging, head and neck pain is becoming increasingly common in Chinese population, which may increase the onset of migraine attacks. ${ }^{49}$ Until now, most current evidence concerning the risk factors of migraine is based on single-center studies with small samples. Hence, further multicenter cohort studies with large samples are needed to verify the mechanisms of these risk factors.

Risks of migraine persistently decline for all populations in period effects. Period effects are usually influenced by a complex set of historical events and environmental factors, such as public health interventions. ${ }^{50}$ The improvement of China's medical insurance system has provided many people with easy access to healthcare, and effective health education and other intervention measures have encouraged people to voluntarily seek treatment for migraine. ${ }^{1}$ The importance of epidemiological methodologies in the study of the disease burden of headache disorders is increasingly recognized. Renewing approaches can enhance our understanding of disease origins patterns, etiology, and risk factors, thereby improving opportunities for treatment and prevention. ${ }^{51}$ The Global Campaign against Headache aims to improve and standardize the methods used in cross-sectional studies, the most important of which is to develop guidelines for consensus-based methodology. 52 Some changes in migraine incidence may be due to the improvements in epidemiological methods used to measure migraine incidence over the last decades. Moreover, the huge burden attributable to migraine has motivated epidemiological studies to determine the risk factors and causes of migraine, some of which may be preventable. Smoking is a modifiable risk factor for migraine. ${ }^{53}$ In China, four national tobacco surveys among adults in 1984-2010 showed that tobacco smoking rates gradually decreased in the general population over the past two decades. $^{54}$ The decrease in smoking prevalence could explain the decreasing incidence during this period. However, the association between environmental tobacco exposure and migraine incidence remains controversial. Although migraineurs worldwide report smoking as a cause of migraine, population-based diary data are extremely limited, and controlled trials establishing a causal relationship between smoking exposure and migraine remain lacking.

Despite GBD filled in the gap in the migraine burden of China, several limitations should be acknowledged. First, the estimates from GBD may be inconsistent with the actual data because of the lack of epidemiological survey data in China and the large heterogeneity among studies. Although GBD collected as much published and unpublished data as possible, the quantity and quality of data on migraine remain limited. For example, the occurrence of migraine at zero before age 5 may produce inconsistent results concerning incidences and may impact the accuracy of the estimated burden. Second, even though the methods used in this study are characterized by unbiased, effective, asymptotic, and superior estimation, the theoretical basis is complex and the practical significance of parameter estimation cannot be explained. Third, the GBD 2019 database only provided the migraine incidence rate and lacked the risk factors that are closely related to migraine, such as lifestyle, living environment, and educational level. Finally, age-period-cohort analysis might lead to ecological fallacies. Hence, based on available information and resource, a scientific hypothesis about the causal relationship of temporal trends has been supported.

\section{Conclusion}

Migraine incidence showed an overall increasing trend from 1990 to 2019 in China. A significant gender difference was found in migraine incidence, which was higher in females than in males. Age is a crucial factor of migraine incidence, with a high risk among adolescents and youths. Period effects showed that the risk of migraine continued to decrease over time. In terms of cohort effects, people born after the 1960 s presented a higher risk of migraine as compared with the whole cohort. The risk characteristics and disease patterns of migraine warrant further investigation to provide early diagnosis, timely interventions, and burden reduction for patients with migraine. 


\section{Ethics and Approvals}

This article does not contain any studies with human participants or animals performed by any of the authors. The review and approval were not required for this research by an institutional review board or ethics committee because this study used a public database with epidemiological data and the article was not contain any studies with human participants or animals performed by any of the authors.

\section{Acknowledgments}

The relevant data in this study can be freely available from the official website of the Global Burden of Disease Study 2019. The content is solely the responsibility of the authors and does not necessarily represent the official view of the Guangdong National Health Commission Guangdong.

\section{Funding}

This project was supported by the Medical Scientific Research Foundation of Guangdong Province (No. A2018162).

\section{Disclosure}

The authors have indicated that they have no conflicts of interest about the content of this article.

\section{References}

1. Stovner LJ, Nichols E, Steiner TJ; GBD 2016 Headache Collaborators. Global, regional, and national burden of migraine and tension-type headache, 1990-2016: a systematic analysis for the Global Burden of Disease Study 2016. Lancet Neurol. 2018;17(11):954-976. doi:10.1016/S1474-4422(18)30322-3

2. Baykan B, Ertas M, Karlı N, et al. Migraine incidence in 5 years: a population-based prospective longitudinal study in Turkey. $J$ Headache Pain. 2015;16:103. doi:10.1186/s10194-015-0589-2

3. Yao C, Wang Y, Wang L, et al. Burden of headache disorders in China, 1990-2017: findings from the Global Burden of Disease Study 2017. J Headache Pain. 2019;20(1):102. doi:10.1186/s10194-019-1048-2

4. Leonardi M, Raggi A. A narrative review on the burden of migraine: when the burden is the impact on people's life. J Headache Pain. 2019;20(1):41. doi:10.1186/s10194-019-0993-0

5. Murray CJ, Lopez AD. Measuring the global burden of disease. N Engl J Med. 2013;369(5):448-457. doi:10.1056/NEJMra1201534

6. Zhou M, Wang H, Zeng X, et al. Mortality, morbidity, and risk factors in China and its provinces, 1990-2017: a systematic analysis for the Global Burden of Disease Study 2017. Lancet. 2019;394 (10204):1145-1158. doi:10.1016/S0140-6736(19)30427-1

7. Rosenberg PS. A new age-period-cohort model for cancer surveillance research. Stat Methods Med Res. 2019;28(10-11):3363-3391. doi: $10.1177 / 0962280218801121$

8. Wu J, Lin Z, Liu Z, et al. Secular trends in the incidence of eating disorders in China from 1990 to 2017: a joinpoint and age-periodcohort analysis. Psychol Med. 2020:1-11. doi:10.1017/ S0033291720002706
9. Guido D, Leonardi M, Mellor-Marsá B, et al. Pain rates in general population for the period 1991-2015 and 10-years prediction: results from a multi-continent age-period-cohort analysis. J Headache Pain. 2020;21(1):52. doi:10.1186/s10194-020-01108-3

10. GBD 2019 Risk Factors Collaborators. Global burden of 87 risk factors in 204 countries and territories, 1990-2019: a systematic analysis for the Global Burden of Disease Study 2019. Lancet. 2020;96(10258):1223-1249. doi:10.1016/S0140-6736(20)30752-2

11. GBD 2019 Demographics Collaborators. Global age-sex-specific fertility, mortality, healthy life expectancy (HALE), and population estimates in 204 countries and territories, 1950-2019: a comprehensive demographic analysis for the Global Burden of Disease Study 2019. Lancet. 2020;396(10258):1160-1203. doi:10.1016/S0140-6736(20)30977-6

12. GBD 2019 Diseases and Injuries Collaborators. Global burden of 369 diseases and injuries in 204 countries and territories, 1990-2019: a systematic analysis for the Global Burden of Disease Study 2019. Lancet. 2020;396(10258):1204-1212. doi:10.1016/S0140-6736(20) 30925-9

13. Kim HJ, Fay MP, Feuer EJ, et al. Permutation tests for joinpoint regression with applications to cancer rates. Stat Med. 2000;19 (3):335-351. doi:10.1002/(SICI)1097-0258(20000215)19:3<335:: AID-SIM336 $>3.0 . \mathrm{CO} ; 2-\mathrm{Z}$

14. Lima CA, Rangel MR, Macedo-Lima M, da Silva AM. Time trends in breast cancer incidence and mortality in a mid-sized northeastern Brazilian city. BMC Public Health. 2012;12:883. doi:10.1186/14712458-12-883

15. Riebler A, Held L, Rue H. Estimation and extrapolation of time trends in registry data-borrowing strength from related populations. Ann Appl Stat. 2012;6:304-333. doi:10.1214/11-AOAS498

16. Smith TR, Wakefield J. A review and comparison of age-periodcohort models for cancer incidence. Stat Sci. 2016;31:591-610. doi:10.1214/16-STS580

17. Jean S, O'Donnell S, Lagacé $\mathrm{C}$, et al. Trends in hip fracture rates in Canada: an age-period-cohort analysis. $J$ Bone Mineral Res. 2013;28:1283-1289. doi:10.1002/jbmr.1863

18. Cao J, Eshak ES, Liu K, et al. Age-period-cohort analysis of stroke mortality attributable to high sodium intake in China and Japan. Stroke. 2019;50:1648-1654. doi:10.1161/STROKEAHA.118.024617

19. Keyes KM, Miech R. Age, period, and cohort effects in heavy episodic drinking in the US from 1985 to 2009. Drug Alcohol Depend. 2013;132(1-2):140-148. doi:10.1016/j.drugalcdep.2 013.01.019

20. Celentano DD, Linet MS, Stewart WF. Gender differences in the experience of headache. Soc Sci Med. 1990;30:1289-1295. doi:10.1016/0277-9536(90)90309-G

21. Smitherman TA, Ward TN. Psychosocial factors of relevance to sex and gender studies in headache. Headache. 2011;51(6):923-931. doi:10.1111/j.1526-4610.2011.01919.x

22. Riley JLIII, Robinson ME, Wise E, et al. Sex differences in the perception of noxious experimental stimuli: a meta-analysis. Pain. 1998;74:181-187. doi:10.1016/s0304-3959(97)00199-1

23. Rist PM, Schürks M, Buring JE, et al. Migraine, headache, and the risk of depression: prospective cohort study. Cephalalgia. 2013;33 (12):1017-1025. doi:10.1177/0333102413483930

24. Martin VT, Behbehani M. Ovarian hormones and migraine headache: understanding mechanisms and pathogenesis-part I. Headache. 2006;46:3-23. doi:10.1111/j.1526-4610.2006.00309.x.

25. Ripa P, Ornello R, Degan D, et al. Migraine in menopausal women a systematic review. Int $J$ Women's Health. 2015;7:773-782. doi:10.2147/JJWH.S70073

26. Pavlovic JM, Akcali D, Bolay H, et al. Sex-related influences in migraine. J Neurosci Res. 2017;95:587-593. doi:10.1002/jnr.23903

27. Pogoda JM, Gross NB, Arakaki X, et al. Severe headache or migraine history is inversely correlated with dietary sodium intake: NHANES 1999-2004. Headache. 2016;56:688-698. doi:10.1111/head.12792 
28. Straube A, Aicher B, Förderreuther S, et al. Period prevalence of selfreported headache in the general population in Germany from 19952005 and 2009: results from annual nationwide population-based cross-sectional surveys. $J$ Headache Pain. 2013;14(1):11. doi:10.1186/1129-2377-14-11

29. Becker C, Brobert GP, Almqvist PM, et al. Migraine incidence, comorbidity and health resource utilization in the UK. Cephalalgia. 2008;28(1):57-64. doi:10.1186/1129-2377-14-11

30. Song TJ, Cho SJ, Kim WJ, et al. Anxiety and depression in probable migraine: a population-based study. Cephalalgia. 2017;37 (9):845-854. doi:10.1177/0333102416653235

31. Haan J, Terwindt GM, van den Maagdenberg AM, et al. A review of the genetic relation between migraine and epilepsy. Cephalalgia. 2008;28(2):105-113. doi:10.1111/j.1468-2982.2007.01460.x

32. Yu SY, Cao XT, Zhao G, et al. The burden of headache in China: validation of diagnostic questionnaire for a population-based survey. J Headache Pain. 2011;12(2):141-146. doi:10.1007/s10194-011-0336-2

33. Wang X, Xing Y, Sun J, et al. Prevalence, associated factors, and impact on quality of life of migraine in a community in Northeast China. J Oral Facial Pain Headache. 2016;30(2):139-149. doi:10.11607/ofph.1584

34. Zhang Y, Shi Z, Hock D, et al. Prevalence of primary headache disorders in a population aged 60 years and older in a rural area of Northern China. J Headache Pain. 2016;17(1):83. doi:10.1186/ s10194-016-0672-3

35. Abu-Arafeh I, Razak S, Sivaraman B, et al. Prevalence of headache and migraine in children and adolescents: a systematic review of population-based studies. Dev Med Child Neurol. 2010;52:1088-1097. doi:10.1111/j.1469-8749.2010.03793.x

36. Lu SR, Fuh JL, Juang KD, et al. Migraine prevalence in adolescents aged 13-15: a student population-based study in Taiwan. Cephalalgia. 2000;20(5):479-485. doi:10.1046/j.1468-2982

37. Goto M, Yokoyama K, Nozaki Y, et al. Characteristics of headaches in Japanese elementary and junior high school students: a school-based questionnaire survey. Brain Dev. 2017;39(9):791-798. doi:10.1016/j.braindev.2017.05.010

38. Jin Z, Shi L, Wang YJ, et al. Prevalence of headache among children and adolescents in Shanghai, China. J Clin Neurosci. 2013;20 (1):117-121. doi:10.1016/j.jocn.2012.02.020

39. Al-Hashel JY, Alroughani R, Shauibi S, et al. Impact of primary headache disorder on quality of life among school students in Kuwait. J Headache Pain. 2020;21(1):1-6. doi:10.1186/s10194020-01124-3

40. Rozen TD, Swanson JW, Stang PE, et al. Increasing incidence of medically recognized migraine headache in a United States population. Neurology. 1999;53(7):1468-1473. doi:10.1212/wnl.53.7

41. Dodick DW. Migraine. Lancet. 2018;391(10127):1315. doi:10.1016/ S0140-6736(18)30478-1
42. Miri A, Nasiri M, Zonoori S, et al. The association between obesity and migraine in a population of Iranian adults: a case-control study. Diabetes Metab Syndr. 2018;12(5):733-736. doi:10.1016/j. dsx.2018.04.020

43. Guldiken B, Guldiken S, Taskiran B, et al. Migraine in metabolic syndrome. Neurologist. 2009;15(2):55-58. doi:10.1097/ NRL.0b013e31817781b6

44. Hua J, Zhang L, Gao D, et al. Prevalence of overweight and obesity among people aged 18 years and over between 2013 and 2018 in Hunan, China. Int J Environ Res Public Health. 2020;17(11):4048. doi:10.3390/ijerph17114048

45. Yang JS, Xu J, Wu XJ. Economic growth and environmental and social health costs. Econ Res. 2013;48:17-29.

46. Chen CC, Tsai SS, Yang CY, et al. Association between fine particulate air pollution and daily clinic visits for migraine in a subtropical city: Taipei, Taiwan. Int $J$ Environ Res Public Health. 2015;12:4697-4708. doi:10.3390/ijerph120504697

47. May A, Schulte LH. Chronic migraine: risk factors, mechanisms and treatment. Nat Rev Neurol. 2016;12(8):455-464. doi:10.1038/ nrneurol.2016.93

48. Ministry of Civil Affairs of the People's Republic of China. Social service development statistics bulletin. Available from: http:// images3.mca.gov.cn/www2017/file/202009/1601261242921.pdf. Accessed March 5, 2021.

49. Safiri S, Kolahi AA, Hoy D, et al. Global, regional, and national burden of neck pain in the general population, 1990-2017: systematic analysis of the Global Burden of Disease Study 2017. BMJ. 2020;368:m791. doi:10.1136/bmj.m791

50. Liu X, Yu C, Bi Y, et al. Trends and age-period-cohort effect on incidence and mortality of prostate cancer from 1990 to 2017 in China. Public Health. 2019;172:70-80. doi:10.1016/j.puhe.2 019.04.016

51. Vos T, Flaxman AD, Naghavi M, et al. Years lived with disability (YLD) for 1160 sequelae of 289 diseases and injuries 1990-2010: a systematic analysis for the Global Burden of Disease Study 2010. Lancet. 2012;380(9859):2163-2196. doi:10.1016/S0140-6736(12) 61729-2

52. Stovner LJ, Al Jumah M, Birbeck GL, et al. The methodology of population surveys of headache prevalence, burden and cost: principles and recommendations from the Global Campaign against Headache. $J$ Headache Pain. 2014;15(1):5. doi:10.1186/1129-2377-15-5

53. Taylor FR. Tobacco, nicotine, and headache. Headache. 2015;55 (7):1028-1044. doi:10.1111/head.12620

54. Wang L, Yu C, Liu Y, et al. Lung cancer mortality trends in China from 1988 to 2013: new challenges and opportunities for the government. Int J Environ Res Public Health. 2016;13(11):1052. doi:10.3390/ijerph13111052
Journal of Pain Research

\section{Publish your work in this journal}

The Journal of Pain Research is an international, peer reviewed, open access, online journal that welcomes laboratory and clinical findings in the fields of pain research and the prevention and management of pain. Original research, reviews, symposium reports, hypothesis formation and commentaries are all considered for publication. The manuscript management system is completely online and includes a very quick and fair peer-review system, which is all easy to use. Visit http:// www.dovepress.com/testimonials.php to read real quotes from published authors. 